Background Genetic polymorphisms, such as the polymorphisms of vitamin D receptor (VDR) and oestrogen receptor (ER) genes play an important role in bone metabolism and the pathogenesis of osteoporosis. Little is known about the role of VDR and ER gene polymorphisms in rheumatoid arthritis (RA), although hormonal factors are highly involved in the evolution of autoimmune disorders.

Objectives We assessed VDR BsmI, ER XbaI and ER PvuII polymorphisms in 50 RA patients as well as 50 healthy subjects.

Methods Gene polymorphism was assessed in peripheral blood mononuclear cells taken from RA patients and healthy controls. After the PCR amplification of DNA isolated from these cells using specific primer pairs, DNA was digested with BsmI, PvuII and $\mathrm{XbaI}$ restriction enzymes. $\mathrm{B}$ versus $\mathrm{b}, \mathrm{X}$ versus $\mathrm{x}$ and $\mathrm{P}$ versus $\mathrm{p}$ alleles, as well as homozygote and heterozygote genotypes were determined by agarose gel electrophoresis. Genotypes were then correlated with the bone density (assessed by DEXA), serum osteocalcin and urinary pyridinolin crosslink concentrations. Disease activity of RA was assessed by ESR and CRP.

Results There is difference between VDR and ER polymorphisms in RA patients versus controls. A significantly higher percentage of RA patients carry the VDR $\mathrm{Bb}$ heterozygote genotype. XbaI and PvuII ER genotypes are also different in RA patients versus controls. There is a correlation between the VDR and ER genotypes, as well as bone density, biochemical markers and laboratory markers of RA activity.

Conclusion It is likely, that VDR and ER polymorphisms are involved in bone metabolism as well as inflammatory events underlying RA.

\section{THU0011 BSM-1 POLYMORPHISM AND BONE MINERAL DENSITY IN POLYMYALGIA RHEUMATICA}

${ }^{1} A$ Daroszewska, ${ }^{1}$ W Taylor, ${ }^{1} J L$ Usher, ${ }^{2}$ RC Bucknall, ${ }^{3}$ RJ Moots, ${ }^{3}$ RN Thompson, ${ }^{2} E J$ Tunn, ${ }^{1}$ WD Fraser. ${ }^{1}$ Department of Clinical Chemistry, The University of Liverpool; ${ }^{2}$ Department of Rheumatology, Royal Liverpool University Hospital; ${ }^{3}$ Department of Rheumatology, University Hospital Aintree, Liverpool, UK

10.1136/annrheumdis-2001.114

Background VDR gene polymorphism has been associated with variations in bone mineral density (BMD) in normal populations, most studies linking the presence of the Bsm-1 restriction site (b) with higher BMD as compared to absence of Bsm-1 restriction site (B). We found that in steroid induced osteoporosis in PMR patients there is an overrepresentation of $\mathrm{bb}$ and that in normal controls, higher BMD is found in Bb heterozygotes (FA Gidden: data submitted).

Objectives To investigate the VDR gene polymorphism frequency and association with BMD in newly diagnosed patients with PMR, prior to treatment with corticosteroids.

Methods Thirty patients with active PMR (fulfilling Bird's criteria), consecutively referred by GP's to the PMR clinic, underwent lumbar spine and hip BMD scanning on a Hologic dual Xray absorptiometer (DXA). $5 \mathrm{ml}$ EDTA blood was obtained from each patient and used for DNA extraction. Polymerase chain reaction (PCR) and agarose gel electrophoresis were used for Bsm-1 site typing.

Results The VDR genotype distribution was: $\mathrm{BB}$ in 6 patients (20\%), Bb in 10 patients (33.3\%) and bb in 14 patients (46.7\%). Mean BMD of lumbar spine (L1-L4) expressed as Z-score was in BB group 0.32 (95\% CI: $-0.47-1.11)$, in Bb group 1.37 (95\% CI: 0.31-2.41) and in bb group 0.46 (95\% CI: $-0.25-1.18$ ). Mean BMD of femoral neck (Z-score) was in BB group -0.05
(95\% CI: -1.5-1.39), in Bb group 0.49 (95\% CI: $-0.24-1.23$ ) and in bb group 0.13 (95\% CI: $-0.39-0.65)$. Mean age of patients was 73.6, SD 7.6. There was no statistically significant difference between groups with regard to age, disease duration and disease activity (measured by ESR, CRP, Pain Visual Analogue Score, Global Disease Activity Score and Health Assessment Questionnaire).

Conclusion There is an overrepresentation of bb in PMR patients (as compared to UK VDR frequencies: BB 20.5\%, Bb $49.7 \%$, bb $29.8 \%)^{1}$ which may reflect VDR polymorphism role in susceptibility to inflammatory conditions e.g. PMR. Heterozygotes $\mathrm{Bb}$ have highest $\mathrm{BMD}$. $\mathrm{Bb}$ genotype may be bone protective for steroid induced osteoporosis.

\section{REFERENCE}

1 Houston LA, et al. Bone 1996;18(3):249-52

\section{THU0012 CLONAL ANALYSIS OF VH AND VL MRNA IN SINGLE B AND PLASMA CELLS FROM RHEUMATOID ARTHRITIS SYNOVIUM AND PERIPHERAL BLOOD}

\begin{abstract}
1,2S Ruzickova, ${ }^{1} \mathrm{O}$ Krystufkova, 'Z Cimburek, 'I Niederlova, ${ }^{3} \mathrm{~J}$ Sinkora, ${ }^{4} \mathrm{O}$ Horvath, ${ }^{2} \mathrm{~T}$ Doerner, ${ }^{1} \mathrm{~J}$ Vencovsky. ${ }^{1}$ Institute of Rheumatology and Laboratory of Gene Expression; ${ }^{2}$ Department of Rheumatology/Immunology, Medical Faculty, Charite, Humboldt University, Berlin, Germany; ${ }^{3}$ Division of Immunology and Gnotobiology; ${ }^{4}$ Department of Immunology, Institute of Microbiology CAS, Prague, Czech Republic
\end{abstract}

10.1136/annrheumdis-2001.115

Background Rheumatoid arthritis (RA) is characterised by a complex infiltration of many cell types including $\mathrm{T}$ and $\mathrm{B}$ lymphocytes, plasma cells, folicular dendritic cells, macrophages and other cells into synovial tissue of inflamed joints. Presence of B and plasma cells results in a local synthesis of multiple pathologic immunoglobulins contributing to the chronic joint inflammatory processes.

Objectives To analyse mRNA from individual B and plasma cells isolated from synovium and peripheral blood of patients with $\mathrm{RA}$, in order to investigate a clonality, $\mathrm{VH}$ and $\mathrm{VL}$ pairing and a molecular structure of produced antibodies.

Methods RA synovial tissue after synovectomy was enzymatically digested. Single synovial B/plasma cells were sorted using immunofluorescent staining with anti-CD19, anti-IgM and anti-CD38. RA peripheral B cells were isolated in the same way without enzyme treatment. cDNA library from each single B and plasma cell was generated. Nested polymerase chain reaction was performed to analyse $\mathrm{VH}$ and $\mathrm{VL}$ gene usage. $\mathrm{VH}, \mathrm{DH}$ and $\mathrm{JH}$ or $\mathrm{VL}$ and JL gene segments were assigned and somatic mutations determined by comparison to germline sequences on the $\mathrm{V}$ BASE/Genbank database. As a control peripheral B-lymphocytes from healthy donor were screened.

Results Analysis of RA synovial mRNA revealed prevalence of C gamma rearranged transcripts that contained rearranged $\mathrm{VH} 1$, $\mathrm{VH} 2, \mathrm{VH} 3, \mathrm{VH} 4, \mathrm{VH} 5$ and $\mathrm{VH} 6$ genes. Utilisation of $\mathrm{VH}$ segments was similar between RA patients and normal subjects, but the accumulation of somatic mutations was elevated in RA synovial and peripheral B cells. Preferential utilisation of a limited number of $\mathrm{VH}$ and $\mathrm{DH}$ gene segments was found. There was an increased frequency of kappa light chains containing unusually long CDR3 when compared to normal peripheral B cells. mRNAs resulting from transcription of non-productive rearrangements were also detected as well as transcripts corresponding to isotype-switching. 